\title{
Perceptions towards Use of Electronic Dental Record at a Dental College, University of Hail, Kingdom of Saudi Arabia
}

\author{
Freah Alshammary ${ }^{1}$, Basel K Alsadoon ${ }^{2}$, Ahmed A Altamimi ${ }^{3}$, Muhammad Ilyas ${ }^{4}$, Ammar A Siddiqui ${ }^{5}$, Ibne Hassan $^{6}$, \\ Mohammad K Alam ${ }^{7}$
}

\begin{abstract}
Aim: This study highlights the use of electronic dental record (EDR) of a dental college at the University of Hail. This study has examined the perceptions of the stakeholders in regard to the objective mentioned above.

Materials and methods: It was a cross-sectional survey. The present study collected data from participants working in the dental clinics at the University of Hail. Face- and content-validated questionnaire was used as a study tool. The data were displayed in numbers and percentages. A Chi-squared test was used to measure the statistical significance. The $p$ value $<0.05$ was considered significant.

Results: There were 166 respondents, out of which 92 (55.4\%) were male and 74 (44.6\%) were female participants. A highly significant result recorded for age group and rank/position for a variable that says using EDR will add to the skills of the dentists. Results showed that using EDR would not slow down the work. A need for a comprehensive training and the interference with the performance of dentists found as two main barriers towards the use of EDR.

Conclusion: This study has pioneered the idea of checking on the perceptions of stakeholders to enquire about the use of EDR in clinics in the Kingdom of Saudi Arabia. It has been reiterated by all the participants that EDR is a need for the clinics in the kingdom but some have reservations about the tedious nature of its use while some were worried about the excessive training they will need to overcome the difficulty of using it. It is observed from the stakeholders' replies that the use of EDR will slow down the work nature in clinics.

Clinical significance: The EDR is commonly used in many developed countries. The proficiency of its use is quite acceptable. The use of EDR in Kingdom of Saudi Arabia is relatively new. The present study measures the perception of its easiness and efficiency in dental practice.

Keywords: Clinics, Electronic dental record, Hail, Perceptions, Kingdom of Saudi Arabia.

The Journal of Contemporary Dental Practice (2020): 10.5005/jp-journals-10024-2891
\end{abstract}

\section{INTRODUCTION}

In the past, there had been a notable development in the use of information technology in health organizations globally, specifically with the introduction of the electronic health record for health specialists in particular for physicians in the past 20 years. ${ }^{1}$ It is worth noting that such a development in information technology was on the other side in dentistry and proof of this development was an enormous increase in the use of a computer on the chairside by dentists. We can see that a huge increase in the percentage of using the computers by dentists in the United States in 1984 was estimated at only $11 \%$ and then jumped to $85 \%$ in $2000 .^{2}$ Hence, these new technologies for dentistry are now available in the market, and there was a study to measure the relationship between such technologies and dentistry and has found that the relationship was increasing and evolving. A research in Canada to assess dentists' responsiveness regarding the use of the new technologies and to determine the presence and use of computers in Canadian dental practitioners' offices found that $60 \%$ of the dentists believed that the use of technology would improve their clinical practice and found that $90 \%$ of the dentists already had computers in their offices. ${ }^{3,4}$ Similar results were also found among British dentists as $77 \%$ are having or announced that they have the intention for acquiring a computer in the future. ${ }^{5}$ The oral health and general health are important and very integrated to each other for the sake of achieving optimum health of an individual. ${ }^{6}$ Dental informatics represented by the electronic dental record (EDR), which is a similar version to the electronic health record, with a greater focus in oral

\begin{abstract}
1,5 Department of Preventive Dentistry, College of Dentistry, University of Hail, Kingdom of Saudi Arabia

${ }^{2,3}$ College of Dentistry, University of Hail, Kingdom of Saudi Arabia

${ }^{4,6}$ Department of Management and MIS, College of Business Administration, University of Hail, Kingdom of Saudi Arabia

${ }^{7}$ Department of Preventive Dentistry, College of Dentistry, Jouf University, Kingdom of Saudi Arabia
\end{abstract}

Corresponding Author: Ammar A Siddiqui, Department of Preventive Dentistry, College of Dentistry, University of Hail, Kingdom of Saudi Arabia, Phone: +966 553226295, e-mail: a.siddiqui@uoh.edu.sa

How to cite this article: Alshammary F, Alsadoon BK, Altamimi AA, et al. Perceptions towards Use of Electronic Dental Record at a Dental College, University of Hail, Kingdom of Saudi Arabia. J Contemp Dent Pract 2020;21(10):1105-1112.

Source of support: Nil

Conflict of interest: None

and maxillofacial region with the ability to store, manage the patient details, and follow the progress of treatment in dental care. The use of EDR, in addition to general medical condition development, has been adapted in many dental practices all over the world. ${ }^{7,8}$ According to the American Dental Association, the accurate recording of patient information is must and very important whether it is manual filing or electronic in which the last one is increasing dramatically as much as dental informatics technology advances effectively and beneficially in dentistry. ${ }^{9}$ For instance,

(c) The Author(s). 2020 Open Access This article is distributed under the terms of the Creative Commons Attribution 4.0 International License (https://creativecommons. org/licenses/by-nc/4.0/), which permits unrestricted use, distribution, and non-commercial reproduction in any medium, provided you give appropriate credit to the original author(s) and the source, provide a link to the Creative Commons license, and indicate if changes were made. The Creative Commons Public Domain Dedication waiver (http://creativecommons.org/publicdomain/zero/1.0/) applies to the data made available in this article, unless otherwise stated. 
a high increase in the level of adaptation of the EDR has been observed in dental clinics in Tennessee state in the United States of America. ${ }^{10}$ Another example is found in a study that majority of the dentists in the United States of America use computers to access to the patient's information which encompasses a huge increase in the use of EDR in the USA. In addition, the high number of EDR was observed in the Scandinavian countries in which the usage of EDR exceeded $90 \%$ in comparison with the use of manual filing in the information storage. ${ }^{11}$ However, when it comes to assess the outcome of the implementation of the dental information technology in the educational environment in Third World countries to achieve maximum health benefits, there are so many obstacles which have affected the successful application of such technology in these countries as compared to the developed world. ${ }^{12,13}$ In Kingdom of Saudi Arabia, the dental informatics is developing and evolving with greater ratio while its application is focused only on the administrative and management parts. ${ }^{14}$ The goal of this study is aimed to provide the perception of EDR in a dental college at the University of Hail. The study tool used for the present study was built on the concept of technology acceptance model (TAM), which is also used in health informatics research.

\section{Materials and Methods}

It was an observational study having a cross-sectional design. Faceand content-validated questionnaire (5-point Likert scale) was used as a study tool. The questionnaire was distributed electronically to the participants working in the college of dentistry in the University of Hail. The respondents of this survey-based study were students, interns, faculty, technicians, and administrative staff. The data collection period for the present study was 2 months. The data were obtained from February 2020 to April 2020 after taking consent from the participant electronically. The questionnaire consisted of two parts: the first part concerned with information about demographic characteristics of the population and part two of the questionnaire contains questions to measure the perceptions of EDR in two themes, that is, first one is the perceived usefulness and second one is the ease of use and the intention to use. The content of the questionnaire was based on the TAM as stated in Flowchart 1 which was constructed up on the previous questionnaire developed by Tange, and TAM by Fred Davis which has been used greatly in health informatics studies. At first, the model indicates the perceived usefulness which measures the use of a certain system to improve the output of the work in the means of performance. Secondly, it measures the perceived ease of use in which how a person believes that such a system will work without additional efforts by indicating that the system is easy to use. $^{15-18}$ The ethical approval was applied through institutional scientific research and ethics committee. The data were displayed as numbers and percentages. It was also displayed as a figure. For

Flowchart 1:Technology acceptance model by Davis ${ }^{18}$

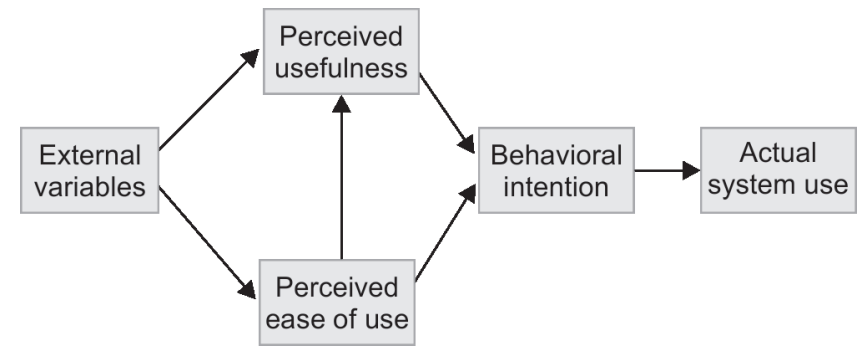

statistical significance, Pearson's Chi-squared test was used. The $p$ value $<0.05$ was considered significant.

\section{Results}

There were 166 respondents, out of which 92 (55.4\%) were male and 74 (44.6\%) were female participants. The demographics as stated in Table 1 were categorized into four sections, that is, gender, age, clinical experience, and the ranks or positions of the respondents. Majority of the respondents were from age group of 20-29 years old which were 149 and $89.8 \%$. Only nine were from 30-39 years age and eight from $40-49$ years of age which make a small portion, that is, almost $10 \%$ of the sample as a whole. Interestingly, none of the responses recorded from the age groups 50-59 years and 60 and above, respectively.

Clinical experience was another part of the demography to check up on the responses based on some experience levels of the targeted sample. The largest numbers of responses were received from 1-5 year-experience category as making it to a total of 118 out of 166 while it makes $71.1 \%$. Having less than one-year experience were $34(20.5 \%)$ respondents, 6-10 years of experience were only six (3.6\%). About 11-15 years experience were only two (1.2\%) and three (1.8\%) respondents each from 16-20 years and 21-25 years experience groups, respectively.

The last part was to bring the rank or position of the respondents into account as well. The largest group of respondents were students 108 (65.1\%) while dental internees were the second largest group with a number of 31 (18.7\%) in total. The lowest group of respondents was administrative with only three (1.8\%) in number while the second lowest were technicians, that is, only $5(3 \%)$. The third-largest group of respondents was the faculty of the university with a total of 19 (11.4\%). There were twelve variables to enquire

Table 1: Demographics/characteristics of participant

\begin{tabular}{lc}
\hline Demographics/characteristics & Number (\%) of respondents \\
\hline Gender & $92(55.4)$ \\
Male & $74(44.6)$ \\
Female & \\
Age in years & $149(89.8)$ \\
$20-29$ & $9(5.4)$ \\
$30-39$ & $8(4.8)$ \\
$40-49$ & $0(0)$ \\
$50-59$ & $0(0)$ \\
60 and above & \\
Clinical experience in years & $34(20.5)$ \\
Less than one year & $118(71.1)$ \\
$1-5$ & $6(3.6)$ \\
$6-10$ & $2(1.2)$ \\
$11-15$ & $3(1.8)$ \\
$16--20$ & $3(1.8)$ \\
$21-25$ & \\
Rank/position & $108(65.1)$ \\
Student & $31(18.7)$ \\
Dental intern & $19(11.4)$ \\
Faculty & $5(3.0)$ \\
Technician & $3(1.8)$ \\
Administrative &
\end{tabular}


Use of Electronic Dental Record in Dental Practice

Table 2: Perception of EDR in dental practice in terms of age group, gender, clinical experience, and rank

\begin{tabular}{|c|c|c|c|c|c|}
\hline Sl. no. & Variable/questions & Age group & Gender & Clinical experience & Rank/position \\
\hline 1 & Using EDR will contribute to the skills of a dentist & 0.01 & 0.57 & 0.08 & 0.01 \\
\hline 2 & Using EDR will increase the efficiency of a practice & 0.17 & 0.74 & 0.24 & 0.12 \\
\hline 3 & $\begin{array}{l}\text { Using EDR will increase the efficiency to accomplish the job quickly and } \\
\text { will save time }\end{array}$ & 0.33 & 0.13 & 0.52 & 0.69 \\
\hline 4 & Using EDR will slow down the performance of practitioners & 0.00 & 0.63 & 0.00 & 0.03 \\
\hline 5 & Using EDR will not save chairside time & 0.54 & 0.03 & 0.48 & 0.11 \\
\hline 6 & Using EDR will slow down the existing workflow of the dental clinic & 0.28 & 0.78 & 0.18 & 0.51 \\
\hline 7 & EDR systems are easy to use & 0.18 & 0.00 & 0.10 & 0.35 \\
\hline 8 & EDR can reduce the physical and mental efforts at work & 0.16 & 0.98 & 0.33 & 0.11 \\
\hline 9 & It is easy to become a skillful EDR user & 0.33 & 0.21 & 0.00 & 0.08 \\
\hline 10 & It is difficult for dental professionals to learn the use of EDR & 0.06 & 0.01 & 0.27 & 0.07 \\
\hline 11 & EDR has a complicated data entry process & 0.58 & 0.08 & 0.11 & 0.35 \\
\hline 12 & A comprehensive training is needed before using EDR & 0.04 & 0.06 & 0.02 & 0.01 \\
\hline
\end{tabular}

$<0.05=$ significant,$>0.05=$ not significant,$<0.01=$ highly significant

about the willing/non-willingness of the respondents about using/ not-using EDR among a targeted sample of respondents as stated in Table 2. In response to the first variable (Q1), that is, using EDR will contribute to the skills of a dentist, a highly significant ratio recorded from age group and rank/position variables as $X^{2}(p=0.01)$, but from gender and clinical perspectives, it has been regarded as not an important requirement for a dentist and considering it not significant recording $X^{2}(p=0.57)$ and $X^{2}(p=0.08)$, respectively. It is highly non-significant from gender perspective though a null hypothesis is already rejected by the age group and rank/position.

In response to Q2 that using EDR will increase the efficiency of a practice, a synonymous rejection is recorded by all the four groups by considering it non-significant with $p$ values as $\mathrm{X}^{2}(p=0.17, p=$ $0.74, p=0.24, p=0.12$ ). Hence, they all believe that using EDR will not increase the efficiency of a practice.

The responses recorded against Q3 (using EDR will increase the efficiency to accomplish the job quickly and will save time) showed an identical relationship or association among all the groups by non-significant $p$ values as $\mathrm{X}^{2}(p=0.33, p=0.13, p=0.52, p=0.69)$ and thus agreeing with the null hypothesis that using EDR will not increase the efficiency to accomplish the job quickly and save time.

We can see a degree of relationship among three groups in answering Q4 (using EDR will slow down the performance of practitioners) with a significance recorded by age group, clinical experience, and rank/position as $\mathrm{X}^{2}(p=0.00, p=0.00, p=0.03)$, respectively, while rejecting the notion that using EDR will not slow down the performance of practitioners but gender stands different with a non-significant value as $X^{2}(p=0.63)$. We can see again gender responding to Q5 (using EDR will not save chairside time.) with a significant value recorded as $\mathrm{X}^{2}(p=0.03)$ in comparison with age group, clinical experience and rank/position where these three accept the null hypothesis by recording their non-significant values as $\mathrm{X}^{2}(p=0.54, p=0.48, p=0.11$ ), respectively. In responding to Q6, all the groups were agreed that using EDR will not slow down the existing workflow of the dental clinic by recording non-significant $p$ values. Apart from gender, all the other three groups, that is, age group, clinical experience, and rank/position, answering Q7 have considered that EDR system is difficult to handle. They have shown their disinterest with non-significant values while on the contrary, it is highly significant from gender perspective and rejected the null hypothesis. Q8 has an identical claim from all the four groups as they rejected the notion that EDR can reduce the physical and mental efforts at work. In relation to Q9, clinical experience group accepts that it is easy to become a skillful EDR user with a highly significant value of $X^{2}(p=0.00)$ while age group, gender, and rank/ position think otherwise with non-significant replies as $X^{2}(p=0.33$, $p=0.21, p=0.08$ ), respectively. In response to $\mathrm{Q} 10$, gender stands different with a highly significant $p$ value $(p=0.01)$ while age group and rank recorded a borderline non-significance but clinical experience stands non-significant with $(p=0.27)$ by accepting that it is not difficult for dental professionals to learn the use of EDR. Q11 has a unanimous answer among all the groups that EDR does not have a complicated data entry process while Q12 is accepted by age group, clinical experience, and rank that a comprehensive training is needed before using EDR with $\mathrm{X}^{2}(p=0.04, p=0.02, p=0.01$ ), respectively, while gender stays different with a slight shift, that is, $\mathrm{X}^{2}(p=0.06)$. The questionnaire was presented with Likert scale with the choices of strongly agree, agree, neutral, disagree, and strongly disagree to measure the degrees of choices of respondents in relation to the answers of each question (Fig. 1). There are some high percentages of choices from gender group while fifth choice was least selected in answers. This study opens a debate from a gender point of view while approaching some answers to the queries which can certainly provide a good debate for future studies of this kind.

\section{Discussion}

Nowadays, we live in the technological era, where technology is incorporated into various parts of our lives with health as an important component, which is developing day by day with the advancement of technology. Dentistry as an integral part of health care sector is equally characterized by dental information technology and is evolving by means of exchange, storage, and retrieving the information in the dental practice. ${ }^{2,19-22}$ As evident from the results, we can see that how the use of EDR system is perceived in terms of making it easy for the dentists/practitioners (Q1-4), ergonomics and its effect on the proficiency of work (Q5), how it can affect the system in clinic as a whole and its ease to handle while giving mental and physical comfort (Q6-8), how easy or difficult to become a user of this system (Q9-11), and how robust training it will need to make use of this EDR system (Q12).

We can conclude from the responses that using EDR system might give or might not give any benefit to the dentists as the 




Fig. 1: Perceptions towards use of EDR

respondents are not clear about its specific advantages to the practitioner/dentist itself though Flores-Mir et al. argue that a high desire was found in Canadian dentists to use EDR. ${ }^{3}$ It is evident from this study that EDR system will not affect the efficiency and proficiency of the work of a dentist as a whole. This study suggests that it might affect the work in a negative direction by making the process even slow and tedious. It is always ideal to use an electronic system for easing the manual work and adding extra precision to the job in hand, but this study categorically rejects the notion that any dentist/practitioner can get any benefit from this system by reducing the time spent beside the chair to treat a patient. However, Delrose and Steinberg, believe that the use of EDR will not only revolutionize the work of the dentists but it will give an impetus to the practitioners for improved data collection and recording. ${ }^{6}$ This study suggests that though using EDR will not affect the existing workflow, it is not easy to use. It can be a barrier to handle this system by the clinics as this study confirms while it suggests that it will not reduce any physical or mental effort at the workplace which adds to its rejection further, while on the contrary
Chauhan et al. believe that a tendency of low or higher adoption can be considered based on smaller practice and dental general specialties, but the importance of adopting EDR in dental colleges and clinics cannot be ruled out. ${ }^{10}$ Considering the use of this system in a clinic, the study revealed that it is hard to become skilled in using this system, but at the same time, it claims that it is easy for the dentists to handle it and the data entry is not a complicated process. It can be recorded as a discrepancy between the notions of becoming skilled in using it and the comfort of handling the system by dentists and entering the data. This study has also revealed that it is not easy to use EDR without training. It encompasses the need for a comprehensive training to use EDR system in a dental clinic, whereas it has been identified by Jathanna et al. earlier that comprehensive training is required for the electronic dental recording and data entry programs. ${ }^{12}$ It is extremely important to envision the barriers identified by the recent study as it claims that slowing down the performance by EDR is an obstacle to use this system. This study has confirmed that comprehensive training is needed to use EDR systems in clinics, thus proving the claim of 
Acharya et al. in his recent study that not only cost and electronic format conversion are strong barriers but poor EDR usability and training deficiency are the strongest obstacles in adopting these systems for the use in dental clinics. ${ }^{8}$

\section{Conclusion}

This study though with its restricted parameters of only selecting a dental college of the University of Hail identified some key concepts about the use of EDR in the dental clinics in Kingdom of Saudi Arabia. It has shown the interests and barriers from the point of view of groups of different experiences and highlighted its concern for bringing this technology into practice on a mass scale in Kingdom of Saudi Arabia. It has been identified with the help of this study that slowing down the performance due to the use of EDR is established and comprehensive training will be required for the users if it is decided to furnish this facility in the dental clinics across Kingdom of Saudi Arabia.

\section{References}

1. World Health Organization. Electronic health records: a manual for developing countries. Manila: Regional Of-fice for the Western Pacific. World Health Organization; 2006.

2. Schleyer TK, Thyvalikakath TP, Spallek H, et al. Clinical computing in general dentistry. J Am Med Inform Assoc 2006;13(3):344-352. DOI: 10.1197/jamia.M1990.

3. Flores-Mir C, Palmer NG, Northcott HC, et al. Computer and internet usage by Canadian dentists. J Can Dent Assoc (Tor) 2006;72(2).

4. Flores-Mir C, Palmer NG, Northcott HC, et al. Perceptions and attitudes of Canadian dentists toward digital and electronic technologies. J Can Dent Assoc (Tor) 2006;72(3).

5. John JH, Thomas D, Richards D. Questionnaire survey on the use of computerisation in dental practices across the Thames valley region. Br Dent J 2003;195(10):585-590. DOI: 10.1038/sj.bdj.4810734.

6. Delrose DC, Steinberg RW. The clinical significance of the digital patient record. J Am Dent Assoc 2000;131:57S-60S. DOI: 10.14219/ jada.archive.2000.0404.

7. Abramovicz-Finkelsztain R, Barsottini C, de Fátima Marin H. Electronic dental records system adoption. In Medinfo 2015. 17-20.

8. Acharya A, Schroeder D, Schwei K, et al. Update on electronic dental record and clinical computing adoption among dental practices in the United States. Clin Med Res 2017;15(3-4):59-74. DOI: 10.3121/ cmr.2017.1380.
9. American Dental Association. Dental Records. Chicago: American Dental Association; 2010.

10. Chauhan Z, Samarah M, Unertl KM, et al. Adoption of electronic dental records: examining the influence of practice characteristics on adoption in one state. Appl Clin Inform 2018;9(03):635-645. DOI: 10.1055/s-0038-1667331.

11. Schleyer T, Song M, Gilbert GH, et al. Electronic dental record use and clinical information management patterns among practitionerinvestigators in the dental practice-based research network. J Am Dent Assoc 2013;144(1):49-58. DOI: 10.14219/jada.archive.2013. 0013.

12. Jathanna VR, Jathanna RV, Jathanna R. The awareness and attitudes of students of one indian dental school toward information technology and its use to improve patient care. Educat Health 2014;27(3):293. DOI: 10.4103/1357-6283.152194.

13. Thierer TE, Delander KA. Improving documentation, compliance, and approvals in an electronic dental record at a US dental school. $J$ Dent Educ 2017;81(4):442-449. DOI: 10.21815/JDE.016.004.

14. Al-Nasser L, Al-Ehaideb A, Househ M. Assessing the current state of dental informatics in Saudi Arabia: the new frontier. Stud Health Technol Inform 2014;202:165-168.

15. Tange HJ. The paper-based patient record: is it really so bad? Comput Methods Programs Biomed 1995;48(1-2):127-131. DOI: 10.1016/01692607(95)01672-g.

16. Davis FD, Bagozzi RP, Warshaw PR. User acceptance of computer technology: a comparison of two theoretical models. Manage Sci 1989;35(8):982-1003. DOI: 10.1287/mnsc.35.8.982.

17. Surendran P. Technology acceptance model: a survey of literature. Int J Busin Soc Res (IJBSR) 2012;2(4):175-178.

18. Davis FD, Venkatesh V. A critical assessment of potential measurement biases in the technology acceptance model: three experiments. Int J Hum Comput Stud 1996;45(1):19-45. DOI: 10.1006/ijhc.1996. 0040.

19. Schleyer TK. Dental informatics: a work in progress. Adv Dent Res 2003;17(1):9-15. DOI: 10.1177/154407370301700104.

20. Patwardhan N, Bhaskar DJ, Bumb SS, et al. Dental informatics in planning an effective oral health information system: a review article. TMU J Dent 2015;2(1):12-16.

21. Chhabra KG, Mulla SH, Deolia SG, et al. Dental informatics in India: time to embrace the change. J Clin Diagnos Res: JCDR 2016;10(3):ZE12. DOI: $10.7860 / J C D R / 2016 / 16970.7453$.

22. Schleyer TK, Thyvalikakath TP, Spallek H, et al. From information technology to informatics: the information revolution in dental education. J Dent Educ 2012;76(1):142-153. DOI: 10.1002/j.00220337.2012.76.1.tb05241.x. 


\section{Section: I}

\section{Please tick $(\checkmark)$ the best choice.}

1. What is your age group?

○ 20-29

○ 30-39

○ 40-49

○ $50-59$

- More than 60

2. What is your gender?

- Male

o Female

3. How long are you in clinical practice?

- Less than 1 year

○ 1-5

○ 6-10

○ 11-15

○ $16-20$

○ 21-25

○ 26-30

- More than 30

4. What is your current rank/position?

- Student year

- Dental intern

- Faculty

- Technician

- Administrative 


\section{Section II}

\section{Please tick $(\checkmark)$ the best choice.}

1. Using electronic dental record will contribute to the skills of a dentist.

O Strongly disagree O Disagree O Neutral O Agree O Strongly agree

2. Using electronic dental record will increase the efficiency of a practice.

O Strongly disagree $\quad$ Disagree $\quad O$ Neutral $\quad O$ Agree $\quad$ Strongly agree

3. Using electronic dental record will increase the efficiency to accomplish the job quickly and will save time.

O Strongly disagree O Disagree O Neutral O Agree O Strongly agree

4. Using electronic dental record will slow down the performance of practitioners.
Strongly disagree
Disagree
Neutral
Agree
O Strongly agree

5. Using electronic dental record will not save chairside time.
Strongly disagree
O Disagree
Neutral
O Agree
O Strongly agree 
6. Using electronic dental record will slow down the existing workflow of the dental clinic.

O Strongly disagree $O$ Disagree ONeutral O Agree OStrongly agree

7. Electronic dental record systems are easy to use.

Strongly disagree $O$ Disagree ONeutral O Agree OStrongly agree

8. Electronic dental record can reduce the physical and mental efforts at work.

Strongly disagree O Disagree ONeutral O Agree OStrongly agree

9. It is easy to become a skillful electronic dental record user.

O Strongly disagree O Disagree ONeutral O Agree OStrongly agree

10. It is difficult for dental professionals to learn the use of electronic dental record user.

Strongly disagree $\quad$ Disagree ONeutral O Agree OStrongly agree

11. Electronic dental record has a complicated data entry process.

O Strongly disagree O Disagree ONeutral O Agree OStrongly agree

12. A comprehensive training is needed before using electronic dental record user.

Strongly disagree $\bigcirc$ Disagree ONeutral O Agree OStrongly agree 